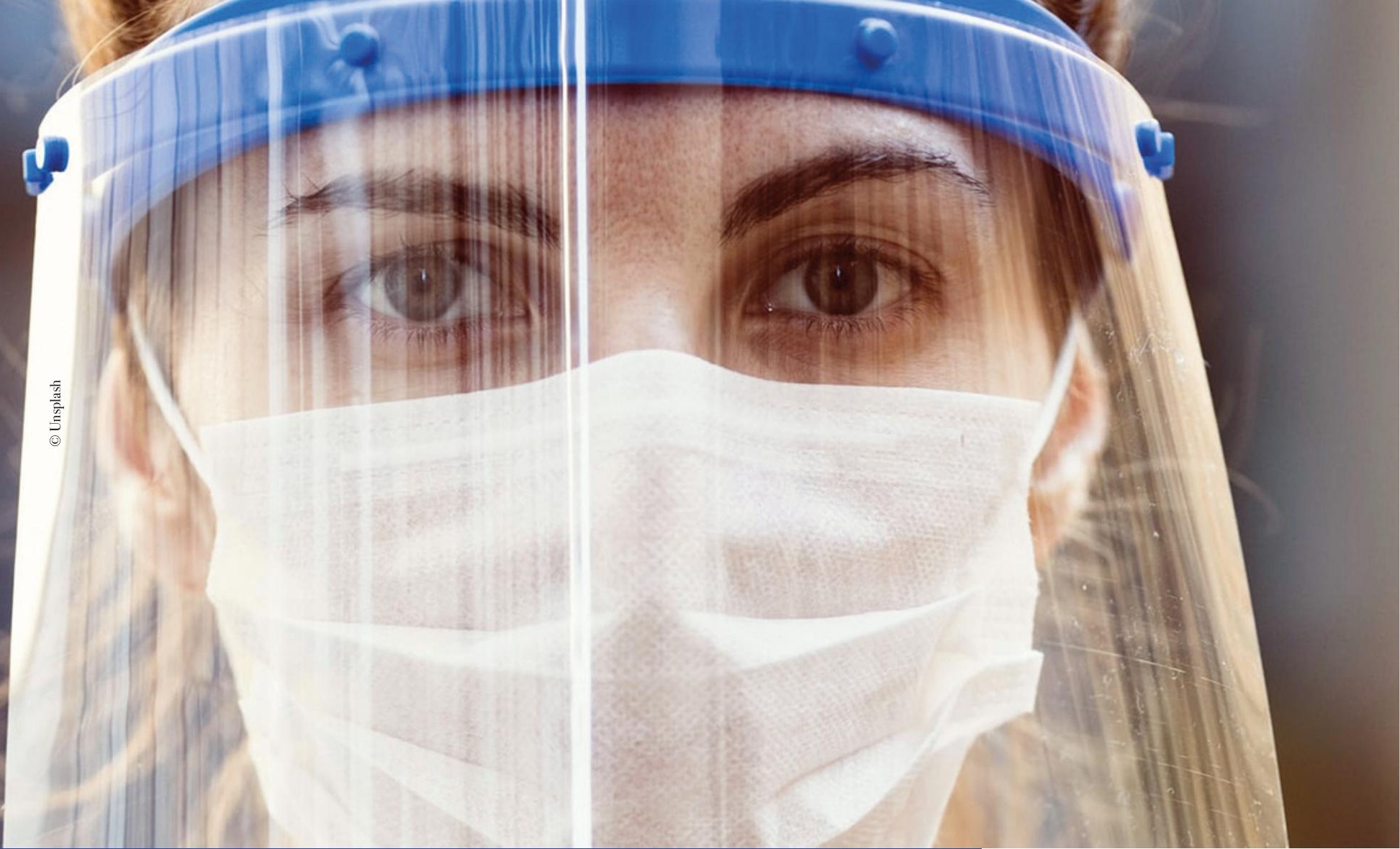

\title{
MATERIALIZAÇÃO DIGITAL DE PROTETORES FACIAIS (FACE SHIELDS):
}

\section{Uma ação a favor da vida}

\section{Eunádia Silva Cavalcante ${ }^{1}$ \\ Helio T. M. Farias ${ }^{2}$ \\ Verner Max Liger de Mello Monteiro ${ }^{3}$}

\section{RESUMO}

- ste artigo apresenta a ação realizada por um grupo de professores do LaboratóErio de Maquetes e Protótipos do CAU/UFRN e do IFRN - campus São Gonçalo do Amarante - que objetiva o desenvolvimento de protetores faciais (face shields), através de prototipagem rápida e fabricação digital, que possam contribuir de forma emergencial para a proteção dos profissionais de saúde do estado do Rio Grande do Norte no atendimento aos pacientes infectados com o novo coronavírus. Trata-se de um tipo de ação que vem sendo desenvolvida por vários FabLabs, Startups, bem como universidades ao redor do mundo, no sentido de suprir a carência e a urgência por equipamentos de proteção, cuja demanda não está sendo atendida pela indústria.
${ }^{1}$ Doutora em Arquitetura e Urbanismo e Professora adjunta da Universidade Federal do Rio Grande do Norte.

2 Doutor em Arquitetura e Urbanismo e Professor adjunto da Universidade Federal do Rio Grande do Norte.

${ }^{3}$ Doutor em Arquitetura e Urbanismo. Docente no Departamento de Arquitetura da UFRN e no curso de edificações do IFRN.

Palavras-chave: Prototipagem rápida; Face shield; COVID-I9.

\section{DIGITAL MATERALIZATION OF FACE SHIELDS: an action for life}

\section{ABSTRACT}

This paper presents an initiative by a group of professors in the Prototype and

Models Laboratory (part of the UFRN School of Architecture) and the IFRN/ São Gonçalo do Amarante Campus, aiming to develop faceshields through rapid pro- 
totyping and digital fabrication as an emergency contribution to the protection of health workers of the Rio Grande do Norte state in Brazil, dealing with patients infected by the new coronavirus. It shares similarities with initiatives being developed by various FabLabs, Startups, as well as universities around the globe, attempting to supply the needed individual protection equipment, which industry production and government distribution cannot keep up with.

Keywords: extension; university; society.

\section{MATERIALIZACIÓN DIGITAL DE FACE SHIELDS: una acción por la vida}

\section{RESUMEN}

Es ste artículo presenta una iniciativa de un grupo de profesores en el Laboratorio Cde Maquetas y Prototipos de la Escuela de Arquitectura (UFRN/Brasil) y del Campus de São Gonçalo do Amarante del IFRN, cuyo propósito es el desarrollo de faceshields utilizando prototipado rápido y fabricación digital, como contribución en carácter de emergencia para la protección de equipos de salud en el estado de Rio Grande do Norte en Brasil en contacto directo con pacientes infectados por el nuevo coronavirus. Este tipo de iniciativa ha sido tomada por FabLabs, Startups y universidades alrededor del globo, como un intento de producir equipamientos de protección individual, cuya alta demanda no se puede suplir a partir de la producción industrial.

Palavras-clave: Prototipado rápido, Face shield, COVID-ı9.

\section{INTRODUÇÃO}

$\mathrm{O}$ contexto no qual se inicia essa ação de extensão nos remete aos dados que levaram a Organização Mundial da Saúde (OMS), em II de março de 2020, a caracterizar a COVID-I9 como uma pandemia, diante do crescente número de casos e sua disseminação global. Até 3I de março de 2020 , já existiam mais de 750 mil casos confirmados ${ }^{\mathrm{T}}$ em todo o mundo, sendo 57.6 Io novos casos em relação ao dia anterior e 36.405 mortes, sendo 3.3OI novas mortes em relação ao dia anterior, segundo aponta a Organização Panamericana de Saúde (OPAS, 202O).

Nesse panorama, com a confirmação de mais de 5 mil casos e 2OI mortes no Brasil, até a tarde do dia 3I de março de 202O, o Ministério da Saúde declarou que havia transmissão comunitária da COVID-I9 em todo o território nacional (OPAS, 2020). O estado do Rio Grande do Norte seguiu a tendência nacional de disseminação dos casos do novo coronavírus, tendo a UFRN tomado a decisão pelo isolamento social da comunidade universitária no dia I7 de março. Em seu boletim epidemiológico, do dia 3i de março, a Secretaria de Saúde Pública do Estado do Rio Grande do Norte (SESAP) contabilizou 82 casos e confirmou I óbito no estado².

A doença é caracterizada por ter alto grau de contágio, sendo transmitida facilmente pelo contato pessoal próximo a pessoas infectadas (sintomáticas ou assintomáticas) ou por meio de tosse ou espirro de pessoas infectadas ou, simplesmente ao tocar objetos ou superfícies já contaminadas e em seguida tocar o nariz, a boca e os olhos (OPAS, 2O2O). Para o enfrentamento da Emergência de Saúde Pública que se instalou no país, os estados têm adotado medidas restritivas de circulação de pessoas, incentivando o distanciamento social, considerada a principal medida para mitigar a disseminação do novo coronavírus. O governo do estado do Rio Grande do Norte, através do decreto $\mathrm{n}^{\circ} 29 \cdot 54 \mathrm{I}$, de 20 de março de $202 \mathrm{O}$, suspendeu e regulamentou o funcionamento de diversas atividades, com vistas a minimizar a

${ }^{1}$ Foram confirmados no mundo 15.012.731 casos de COVID-19 (247.225 novos em relação ao dia anterior) e 619.150 mortes (7.097 novas em relação ao dia anterior) até 23 de julho de 2020. (OPAS, 2020).

${ }^{2}$ Foram confirmados no Rio Grande do Norte 46.187 casos confirmados e 1.656 óbitos até 23 de julho de 2020. (SESAP). 
circulação de pessoas e, assim, conter o contágio. No entanto, alguns serviços são considerados essenciais à população e, por isso, continuam funcionando, como é o caso dos serviços de saúde, supermercados, drogarias, atividades policiais, entre outros.

Os profissionais da área da saúde estão na linha de frente no combate ao novo coronavírus, lidando diariamente e diretamente com pessoas infectadas, sendo recorrente, em todo o mundo, a contaminação e o alto índice de mortalidade desses profissionais $^{3}$, já que são expostos à alta carga viral. Nesse cenário, torna-se extremamente importante proteger as equipes de saúde e também assegurar a saúde do paciente através do uso de Equipamentos de Proteção Individual (EPIs) para aqueles que lidam com pacientes suspeitos ou diagnosticados com a COVID-I9. A Agência Nacional de Vigilância Sanitária (2O2O) cita em sua Nota Técnica GVIMS/ GGTES/ANVISA No $\mathrm{O}_{4} / 2 \mathrm{O} 2 \mathrm{O}$, os tipos de EPIs que devem ser utilizados na prevenção e controle da assistência aos casos suspeitos ou confirmados de infecção pelo novo coronavírus. São eles: máscara cirúrgica, máscara de proteção respiratória, luvas, protetor ocular ou protetor de face (face shield ou faceshield), capote ou avental, gorro e álcool gel a 7o\%. No entanto, devido à magnitude da pandemia, e a necessidade em larga escala de fornecimento de EPIs, a OMS se pronunciou ${ }^{4}$ quanto à preocupação em relação a falta dos Equipamentos de Proteção Individual para os profissionais de saúde, fato reforçado no Brasil pela Associação Médica Brasileira, que indica que muitos profissionais estão trabalhando sem os equipamentos essenciais para evitar a contaminação pelo novo coronavírus (AMB, 2O2O).

Neste contexto de pandemia, a sociedade mundial está sendo convocada a unir esforços no sentido de conter a disseminação do coronavírus, tomando medidas preventivas que busquem a minimização dos casos de COVID-I9 para evitar o colapso do sistema de saúde (FERGUSON et al, 2020). Neste sentido, observa-se, por iniciativa de várias entidades ${ }^{5}$ e pessoas físicas ao redor do mundo, a criação de modelos de arquivo de código aberto para protetores faciais, de forma que possam ser reproduzidos por qualquer pessoa que disponha de equipamentos de impressão $3 \mathrm{D}$, como forma de responder à necessidade aguda e crescente de equipamentos para proteção das equipes médicas na linha de frente contra o COVID-I9, que estão escassos no mercado.

Se comparado a outros EPIs, como máscaras e trajes cirúrgicos, a produção de faceshields dispensa insumos e equipamentos voltados para material têxtil, podendo ser produzidos com equipamentos de impressão ${ }_{3} \mathrm{D}$, cujo grau de difusão já permite a fabricação caseira de objetos (RAYNA e STRIUKOVA, 2OI6). Também em comparação aos EPIs têxteis,

\footnotetext{
enquanto máscaras médicas têm durabilidade limitada e pouco potencial de reprocessamento, face shields podem ser reutilizados indefinidamente e são facilmente limpos com água e sabão, ou desinfetantes caseiros. São confortáveis no uso, protegem os portais de entrada viral, e reduzem o potencial para autoinoculação ao evitar que o usuário de toque a face. (PERENCEVICH, DIEKEMA e EDMOND, 2O2O, p. 2252) ${ }^{6}$
}

Desta forma, o grupo de professores do Laboratório de Maquetes e Protótipos (Labmaq) do curso de Arquitetura e Urbanismo da UFRN, juntamente com um grupo de professores do IFRN - Campus São Gonçalo do Amarante (SGA), decidiu agir e direcionar todo esforço intelectual e material disponível para a execução de uma ação de extensão que auxiliasse na mitigação das consequências da pandemia no estado do Rio Grande do Norte. Para tanto, foram registrados de forma extemporânea dois projetos de extensão que são complementares: "Materialização digital como instrumento de combate ao novo coronavírus: Produção de protetores faciais" (PROEX/UFRN) e "Produção de protetores faciais em combate à COVID-I9" (IFRN/SGA).
${ }^{3}$ Em abril, a Associação Médica Brasileira lançou uma nota demonstrando preocupação com os profissionais da linha de frente de combate ao novo coronavírus derivada do histórico de médicos infectados e mortos no exterior. "Na China, por exemplo, são mais de 3.387 profissionais de saúde infectados. Na Itália, são 5.760 . Mesmo em locais onde os médicos têm acesso aos equipamentos de segurança corretos, há grande incidência de contágio e infecção. [...]" (FIOCRUZ, 2020)

${ }^{4} O$ chefe da Organização Mundial de Saúde (OMS) Tedros Adhanom Ghebreyesus pediu o aumento da produção de equipamentos médicos e suprimentos, devido a demanda crescente e urgente trazida pela pandemia da COVID-19. "Pedimos que os países trabalhem com empresas para aumenta a produção, garantir a livre circulação de produtos essenciais para a saúde e a distribuição igualitária destes produtos, baseado nas necessidades", destacando, especialmente, os países da África, Ásia e América Latina. (ONU, 2020)

${ }^{5}$ O Repositório online de modelos para impressão 3D Thingiverse (www.thingiverse.com) apresenta 980 resultados para o item "faceshield", em busca de julho de 2020, apresentando variações de modelos de equipamentos de segurança adaptados a necessidades específicas. 


\section{OBJETIVOS}

A presente ação tem como objetivos a produção de protetores faciais (face shields), Autilizando-se de prototipagem rápida e fabricação digital, para compor o equipamento de proteção individual (EPI) dos profissionais de saúde do estado do RN e o desenvolvimento de um modelo, bem como a produção manual, de protetores faciais para recém-nascidos de forma a possibilitar o contato seguro entre a mãe infectada pelo coronavírus e o seu bebê.

\section{A PRODUÇÃO DOS PROTETORES FACIAIS}

$\mathrm{O}$ s protetores faciais (face shields) são um elemento complementar de proteção contra o contato com aerossóis que podem conter elementos virais, criando uma barreira entre o meio e as partes da face que permanecem expostas, mesmo quando são equipados com a máscara (cirúrgica e/ou de proteção respiratória) e os protetores oculares (CHU et al, 2O2O). Ainda que protetores deste tipo sejam fabricados industrialmente em distintos modelos, as instituições de saúde não os possuem em quantidade suficiente para atender a súbita demanda gerada pelas atividades de cuidado com pacientes infectados pelo vírus SARS-CoV-2 (ONU, 2O2O).

Esta realidade provocou iniciativas independentes, presenciadas em diferentes pontos do mundo, por grupos de fabricadores (makers) que têm acesso, principalmente, a equipamentos de impressão $3 \mathrm{D}$, no sentido de produzir EPIs e outros equipamentos de suporte às atividades dos profissionais de saúde. Os modelos de face shield desenvolvidos e compartilhados livremente através da internet consistem de dois elementos principais: o suporte, que permite o ajuste do equipamento à cabeça do usuário e sustenta a viseira, geralmente impresso em ${ }_{3} \mathrm{D}$ através da tecnologia FDM (Fused Deposition Modeling); e a viseira, principal elemento de proteção, elemento transparente feito em folha de policarbonato ou acetato a partir de corte, automatizado ou manual. Há modelos que utilizam o material acetato para construir também o suporte e elásticos para realizar o ajuste à cabeça (Figura I).

Figura r: Faceshield com suporte em acetato

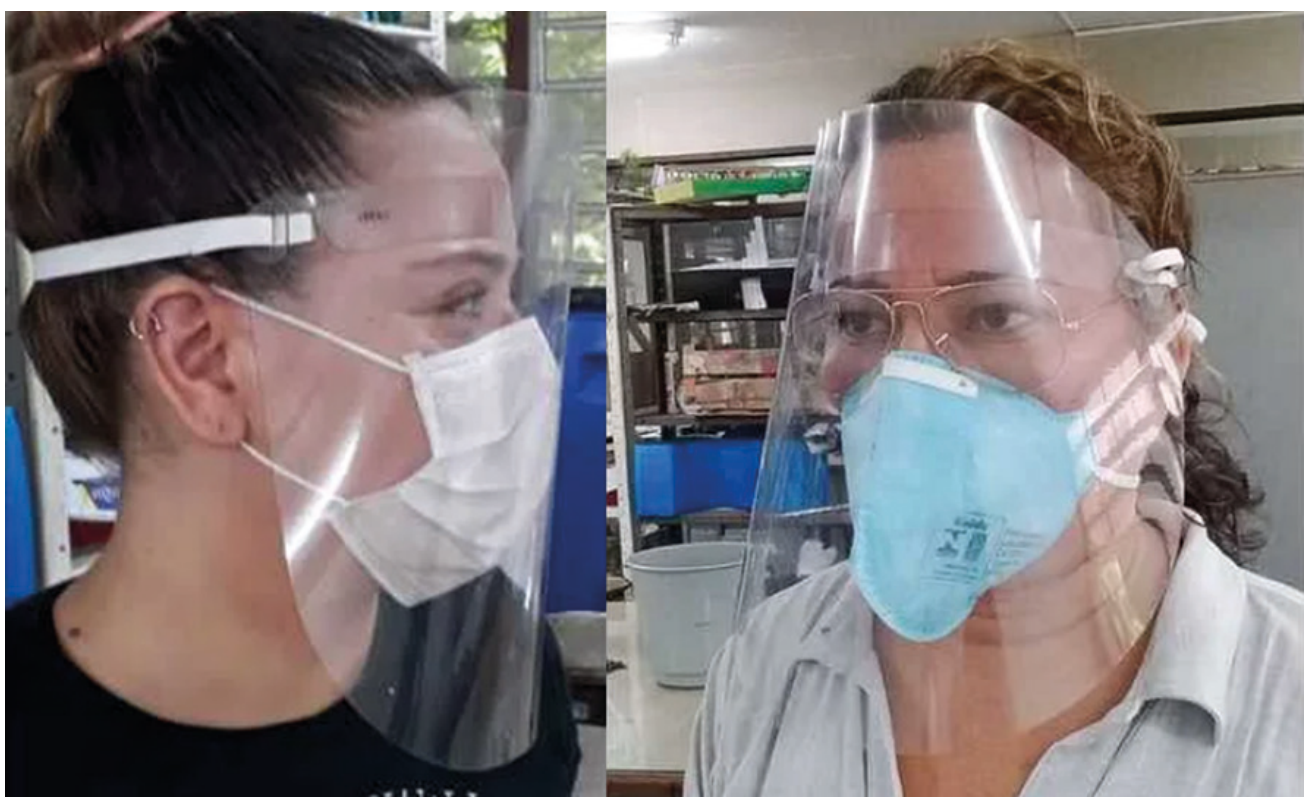

Fonte: NOME e QUEIROZ, $202 \mathrm{O}$.

A iniciativa aqui descrita teve início a partir de testes de impressão de suportes em impressoras ${ }_{3} \mathrm{D}$ do tipo FDM realizados utilizando-se modelos compartilhados por grupos internacionais de makers, atestando a viabilidade de produção em pequena escala com o uso de duas impressoras 3 D disponíveis no LabMaq/UFRN e no IFRN/

${ }^{7} \mathrm{Na}$ ausência de estudos consolidados sobre a fabricação de faceshields em março de 2020, selecionaram-se para experimentação modelos com diferentes relações de robustez/tempo de produção. 
SGA, a partir de filamentos plásticos PLA, ABS e PETG. Dentre os vários modelos compartilhados, três foram selecionados para realizar a materialização?. Os dois primeiros, apesar do bom funcionamento, foram considerados inviáveis para este projeto por demandarem entre três e cinco horas para impressão. O terceiro modelo obtido, por sua vez, possibilitou a impressão em uma hora, além de ter boa ergonomia e proteger adequadamente as laterais do rosto.

O modelo inicial foi substituído por um modelo simplificado (Figura 2) que, por ter impressão mais rápida, permitia a fabricação de dez a quinze suportes por dia, com os recursos então disponíveis ao grupo. Este modelo conta com a flexibilidade inerente ao plástico impresso em FDM para ajustar-se à cabeça do usuário, com a adição de um elástico comum enlaçado à parte posterior para aumentar a firmeza deste ajuste. Com o compromisso de oferecer sessenta unidades semanais às instituições de saúde, o grupo iniciou uma campanha de divulgação do trabalho em finais do mês de março de 202O. A avaliação da demanda de equipamentos neste momento, no entanto, apontava que seria necessária uma produção mais veloz e em maior quantidade para que a campanha pudesse suprir uma quantidade maior de pedidos de instituições.

Figura 2: Modelo simplificado

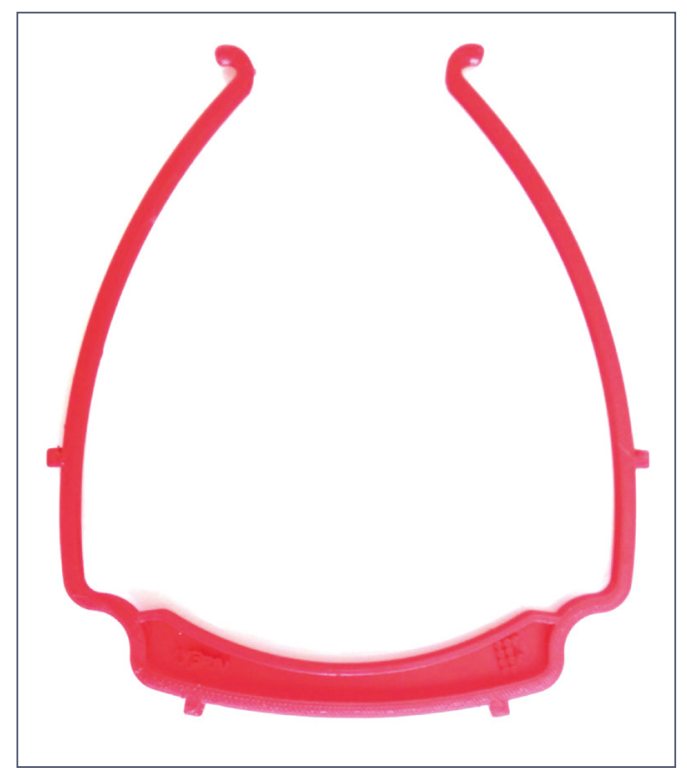

Fonte: Acervo dos autores

Tendo em vista o trabalho prévio do grupo na confecção de elementos arquitetônicos através da técnica de corte a laser de chapas de madeira e acrílico, e a disponibilidade no mercado local dos equipamentos e materiais necessários para este tipo de atividade, foi desenvolvido um novo modelo de suporte, utilizando a mesma base geométrica do modelo impresso em filamento plástico. O modelo cortado em acrílico $5 \mathrm{~mm}$ foi testado e, devido à diferença de flexibilidade entre o plástico resultante da impressão FDM e o acrílico, ajustado para ter uma maior abertura padrão, melhorando o conforto ao usuário.

Outra adaptação feita foi a divisão da peça única em duas partes, com a adição de um elemento central de travamento, feita com o intuito de otimizar o uso da placa de acrílico, minimizando o desperdício de material: cada placa de acrílico com dimensões $2 \mathrm{~m}$ x Im pode, desta maneira, produzir I80 unidades de suportes para face shield (Figura 3). A projeção de custo para a fabricação da unidade de protetores neste modelo mostrou-se favorável quando comparada ao modelo impresso em FDM, ao mesmo tempo que trazia grande vantagem para a velocidade de fabricação: havendo recursos suficientes, seria possível fazer o corte de até 36o unidades diárias. Para ambos os modelos, a viseira foi construída a partir de folhas de acetato de espessura o.3mm, cortados a laser ou manualmente. 
Figura 3: Disposição de peças para corte em acrílico, em formato CAD.

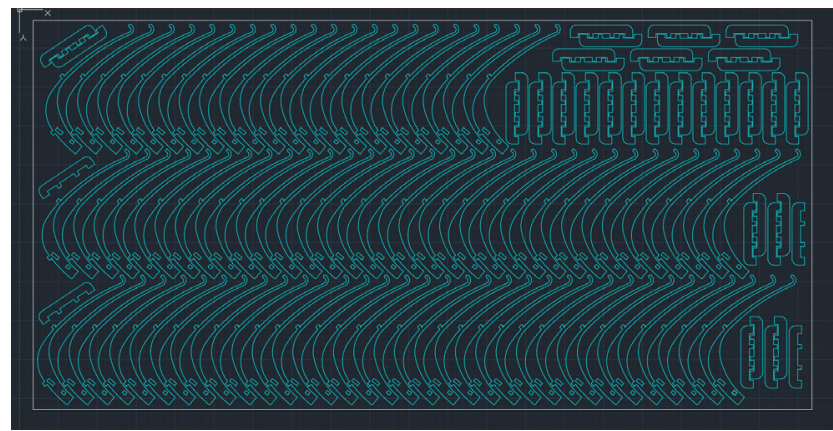

Fonte: Acervo dos autores

Os recursos para a fabricação do material foram viabilizados, inicialmente, através de uma campanha online (Figura 4), com a disponibilização de conta corrente para depósitos de doações individuais, ao mesmo tempo que foram divulgados os caminhos para requisição, via e-mail, dos protetores para instituições de saúde. Os recursos iniciais angariados através desta campanha permitiram a realização das primeiras entregas de face shields cortados em acrílico, e a publicidade destas ações trouxeram novos aportes de recursos através de doações de instituições, que permitiram a continuidade da iniciativa.

A produção de suportes em impressão FDM teve continuidade, com a adição de uma nova impressora disponibilizada voluntariamente por um aluno do curso da Escola de Ciências e Tecnologia (ECT/UFRN). A equipe consolidou-se, neste momento, totalizando 9 professores do LabMaq e do IFRN/SGA, 3 técnicas administrativas da UFRN, 5 alunos da UFRN e IFRN/SGA, e familiares da equipe que se voluntariaram para auxiliar no processo de produção.

Figura 4: Banner da campanha de doações.

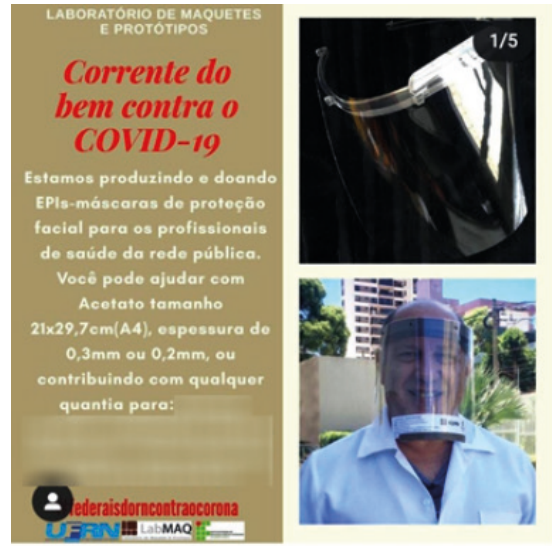

Figura 4: Banner da campanha de doações.

A produção dos equipamentos foi organizada de modo a ocorrer na residência dos participantes envolvidos. A partir de um registro diário de estoques, compartilhado entre o grupo, os insumos de produção (acetato, elásticos, sacos plásticos para a distribuição e etiquetas para instruções de uso) e os suportes de acrílico, cortados em uma empresa local, ou impressos em FDM, foram distribuídos para os endereços dos montadores. Depois de cortados os suportes de acrílico, o material é enviado para colagem, e posteriormente é montado junto à folha de acetato de tamanho $\mathrm{A}_{4}$, com o,3 $\mathrm{mm}$ de espessura, devidamente perfurada para encaixar no suporte de acrílico, conjunto de ligas estabilizadoras e etiqueta de identificação do projeto.

As circunstâncias de isolamento social às quais o grupo esteve submetido levaram à contratação de serviços de entrega para atender a todas as necessidades de movi- 
mentação de materiais, com roteiros planejados diariamente. Uma vez concluída a montagem (Figura 5), os protetores foram disponibilizados para serem recolhidos pelas instituições inscritas para doação diretamente nas residências de três professores, que serviram como pontos de distribuição.

Figura 5: Fabricação e montagem dos protetores e kits

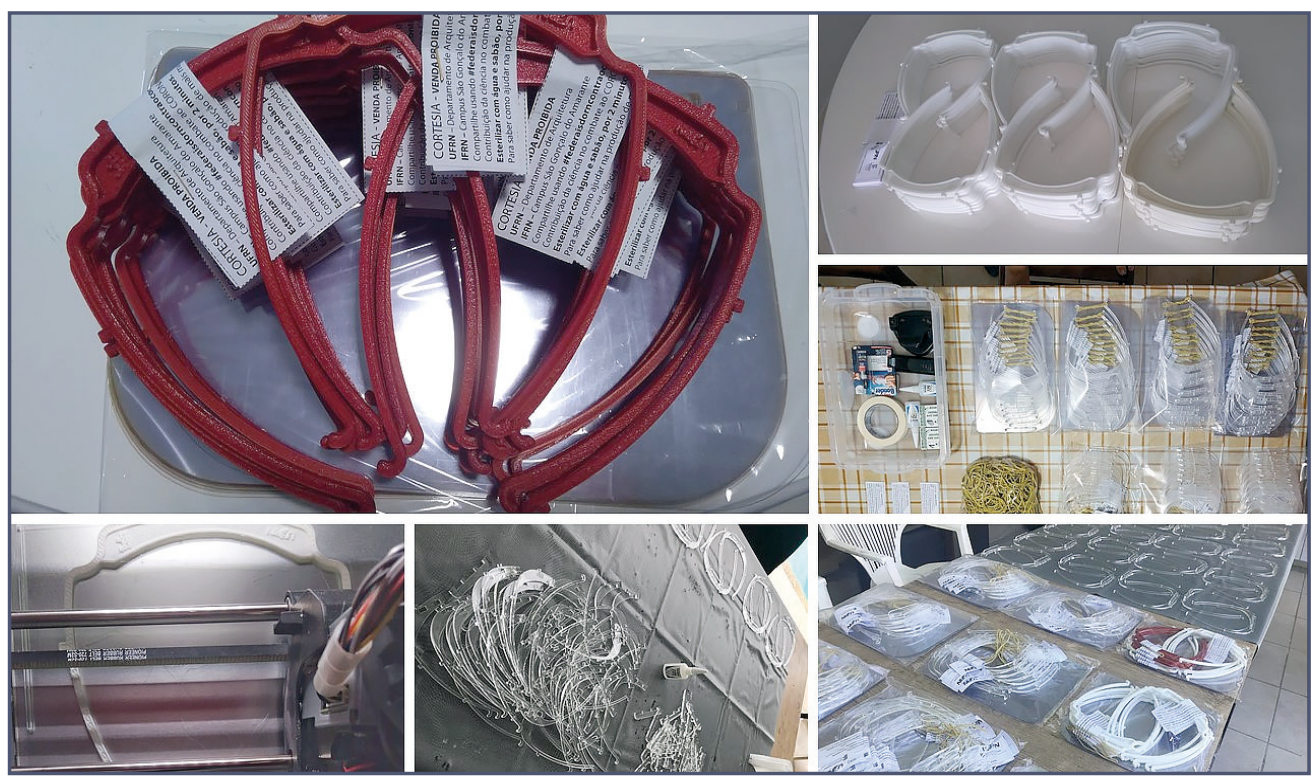

Fonte: Acervo dos autores

A ampla distribuição do material, cuja produção ao longo das primeiras três semanas alcançou a cifra de 3000 unidades, pôde atender à demanda emergencial de uma grande quantidade de instituições e profissionais de saúde, e, ao mesmo tempo, gerou um volume de testes de uso em circunstâncias reais, que não poderíamos obter em experimentos caseiros. A resposta dos usuários aos aspectos de conforto, durabilidade e higienização dos equipamentos foi avaliada a partir de contatos diretos e de formulários enviados por e-mail. Estes relatos levaram ao desenvolvimento de um novo modelo do suporte em acrílico, com maior abertura e hastes mais delgadas (e, portanto, mais flexíveis) de maneira a minimizar o risco de rompimento durante o uso do equipamento (Figura 6).

Figura 6: Sobreposição do modelo em acrílico original (azul) e do modelo ajustado (vermelho).

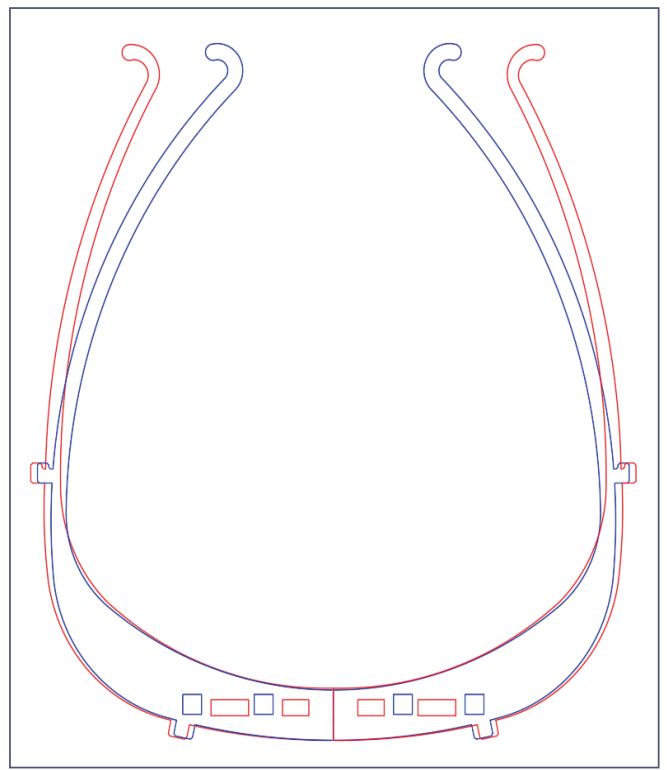

Fonte: Acervo dos autores 
No tocante à distribuição, as demandas institucionais, predominantemente oriundas de secretarias municipais de saúde, hospitais e unidades básicas de saúde, são recebidas pelo e-mail do LabMaq-UFRN, analisadas pela equipe e atendidas em poucos dias. Visando melhor distribuir os EPIs pelo território estadual, o grupo adotou a estratégia de limitar os pedidos a algumas dezenas, a depender do porte da instituição, alcançando assim um número maior de localidades. Apesar disso, a região metropolitana recebe maior atenção, uma vez que concentra maior população e aglomerações e, por consequência, potencialidade de disseminação da COVID-Ig.

Paralelamente à distribuição, todos os resultados são divulgados nas redes sociais, fazendo com que a ação aumente o seu alcance, de modo que mais instituições conheçam o trabalho e solicitem os protetores faciais para proteger os seus profissionais da saúde. Outra função da publicização das informações é dar transparência ao uso dos recursos doados pelas pessoas físicas e jurídicas que colaboram para manter a ação em andamento.

Após o alcance da produção de um número significativo de protetores faciais para as equipes de saúde, o grupo de professores passou a discutir sobre a viabilidade da produção de protetores faciais para recém nascidos. Com a mesma preocupação com critérios como disponibilidade de materiais atóxicos no mercado da cidade, facilidade de montagem manual, capacidade de resistência dos materiais ao processo de higienização, e adequação aos procedimentos em berçários e UTIs neonatais, foram desenvolvidos modelos testados pela médica Ana Cecília Lima, coordenadora do alojamento conjunto do Hospital Santa Catarina. A pediatra, que colaborou com essa fase do projeto, concedeu entrevista ao Agora RN, em 24 de abril de $202 \mathrm{O}$, e ressaltou a importância dos protetores faciais para bebês:

\begin{abstract}
As máscaras são de grande utilidade, pois permitem a proximidade entre mãe e filho de forma mais segura, preservando a saúde do bebê. Até o momento se sabe que não há transmissão vertical - quando o contágio ocorre ainda durante a gestação - e os casos de transmissão da mãe para o filho ocorrem após o parto. Dessa forma, as máscaras para os bebês possibilitam criar uma barreira, contribuindo para sua proteção.
\end{abstract}

Sobre os modelos para bebês, enviados para teste, a médica fez sua avaliação, citando: "A experiência foi fantástica, a máscara ficou bem acoplada e com certeza é uma aquisição muito benéfica para os bebês".

Com a aprovação pela equipe da saúde que lida com bebês no ambiente hospitalar, o modelo entrou em produção, através de um processo manual, segundo as etapas descritas a seguir (Figura 6): I- Corte do suporte polietileno (macarrão de piscina); 2- Corte do acetato; 3 - Proteção das bordas de acetato; 4 - Inserção do elástico; 5-Fixação do suporte com fita dupla face; 6- Fixação da etiqueta; 7- Montagem dos kits para distribuição.

Figura 7: Etapas da produção do Protetor Facial para bebês

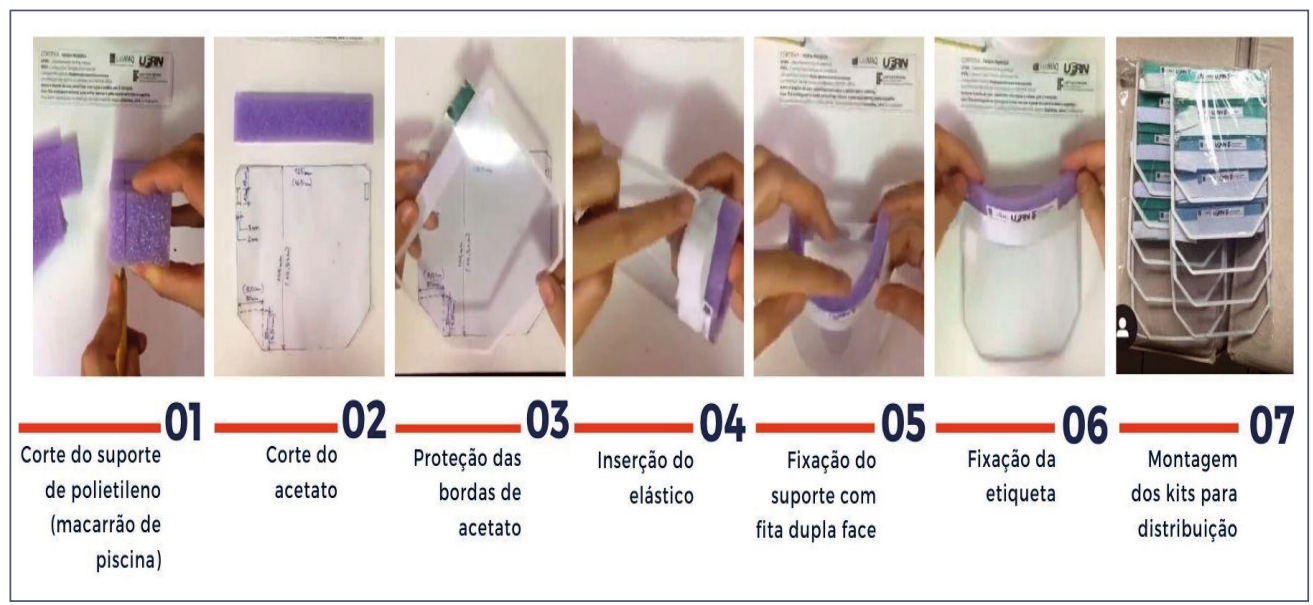

Fonte: Acervo dos autores 
A equipe considerou importante a divulgação do processo de confecção dos protetores faciais para bebês de forma que as mães que necessitarem do equipamento fora do ambiente hospitalar pudesse confeccionar para o uso doméstico. Desta forma, foi produzido um vídeo informando sobre os materiais necessários, medidas e processo de montagem que foi divulgado nas redes sociais do projeto e que está disponível no link: Como fazer máscaras faciais para bebês em casa.

Figura 8: Etapas da pesquisa e produção dos tipos de Protetores Faciais

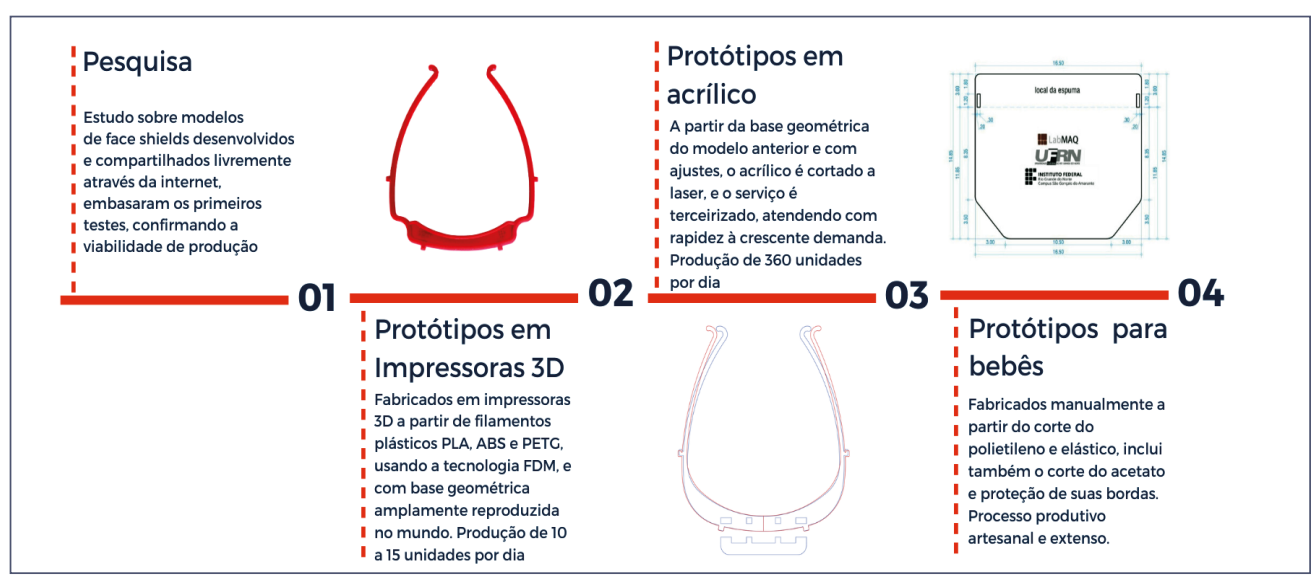

Fonte: Acervo dos autores

A partir da experiência descrita, é possível sintetizar através da figura 8 as etapas do processo de produção dos protetores faciais, desde as pesquisas iniciais, envolvendo os primeiros testes e validação do modelo fabricado em impressora $3 \mathrm{D}$, passando pela adoção do suporte em acrílico e chegando, por fim, ao modelo mais recentemente desenvolvido e confeccionado, voltado para bebês.

\section{RESULTADOS E ALCANCE DO PROJETO NA REDE DE SAUDE DO RN}

Daralelamente à produção dos protetores faciais, foi possível observar o avanço da doença no estado (Figura 8), sendo necessário acelerar o ritmo da produção para atender à crescente demanda que surgiu a partir do aumento do número de solicitações feitas pelas secretarias de saúde dos municípios e diretamente pelas instituições de saúde, desde as unidades básicas até os hospitais regionais. Após trinta e oito dias de início dessa ação, a produção dos protetores faciais ultrapassou o número de 4000 unidades montadas e distribuídas para i6 das I9 microrregiões do estado, alcançando um total de 5O municípios (Figura 9) e I52 instituições públicas de saúde beneficiadas. Nesta fase atual da ação, estão sendo feitas, além da distribuição para atender novas requisições, a complementação de pedidos anteriores que não tinham sido atendidos em sua totalidade, e a nova produção de protetores para recém-nascidos.

Figura 9: Mapa de casos confirmados da COVID-I9 por município, com taxa para cada Ioomil hab.

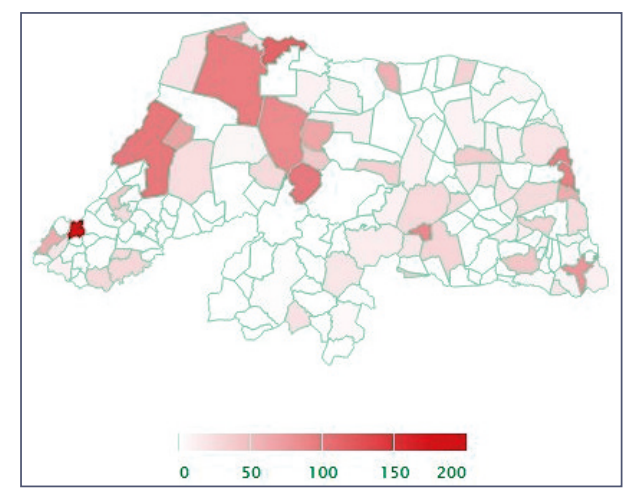

Fonte: CoronavirusRN - LAIS/HUOL/ UFRN (2020). 
Figura Io: Mapa do alcance do projeto por microrregião e quantidade de protetores distribuídos.

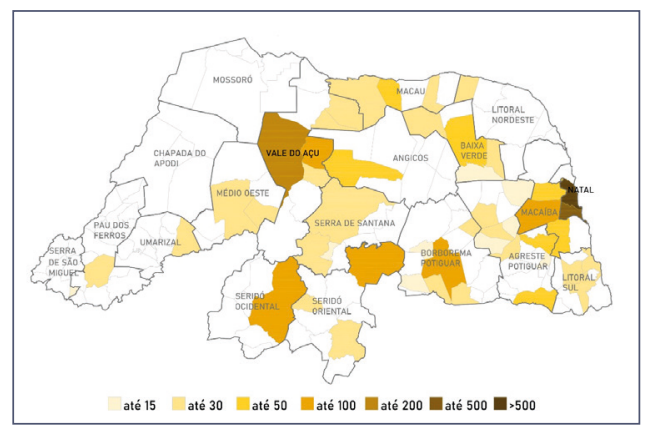

Fonte: Acervo dos autores

Para que a produção dos protetores atendesse de forma mais imediata possível as necessidades da rede pública de saúde, foi fundamental o envolvimento voluntário das pessoas que compõem as equipes de montagem e distribuição dos kits, além dos autores deste artigo. Essas contribuições foram feitas por professores, servidores técnico-administrativos e estudantes da UFRN; estudantes do IFRN/SGA e voluntária externa.

Destaca-se ainda a adesão de um número significativo de pessoas físicas e jurídicas que contribuíram financeiramente ou através da doação direta de insumos, dentre os quais a Fundação Ameropa, o IFRN/SGA, a FUNPEC e o SINDUSCON/RN, para o êxito alcançado pelo projeto.

Como forma de dar visibilidade e transparência a todo esse esforço coletivo empreendido de forma voluntária por servidores e estudantes de instituições públicas de ensino, que têm o compromisso com a sociedade como base fundamental de suas ações, utilizamos as redes sociais do Labmaq/UFRN, tanto no sentido de divulgação do projeto, quanto para a prestação de contas da produção e distribuição dos protetores faciais, divulgando as instituições beneficiadas com dados atualizados semanalmente. Ao mesmo tempo, recebemos por meio das redes sociais o agradecimento das equipes que foram beneficiadas por essa ação (Figura II).

Figura ro: Mapa do alcance do projeto por microrregião e quantidade de protetores distribuídos.

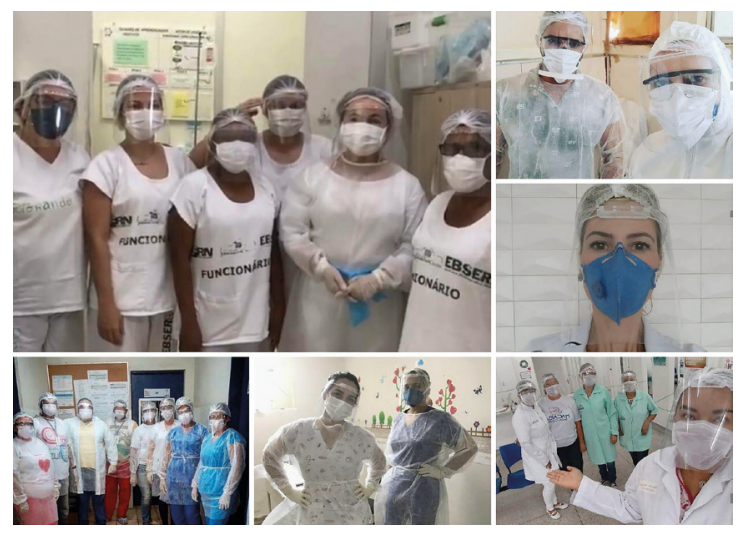

Fonte: Acervo dos autores

Acreditamos que essa interação direta com as instituições e a sociedade, bem como a relevância da ação no sentido de suprir a falta de equipamentos de proteção para as equipes de saúde do estado, chamou a atenção da mídia, dentre tantas outras ações que vêm sendo empreendidas de modo emergencial, de forma que os canais locais de TV e jornais publicaram matérias e entrevistas ampliando a projeção desse projeto para além das instituições que o abrigam, ampliando o seu alcance no estado, bem como divulgando a importância do conhecimento científico e das instituições federais de ensino frente à sociedade, principalmente em situações extremas como essa provocada pela pandemia. 


\section{CONSIDERAÇÕES FINAIS}

Ressalta-se a capacidade de resposta dada pelo grupo de professores, servidores e esRudantes de instituições públicas de ensino a um problema de caráter emergencial, utilizando do conhecimento científico aplicado em pesquisas desenvolvidas em seus laboratórios e ambientes de ensino sob a forma de uma ação de extensão em benefício da sociedade do Rio Grande do Norte, demonstrando o compromisso dessas instituições com os pilares basilares da educação de qualidade que os sustentam: o ensino, a pesquisa e a extensão.

O compromisso em desenvolver um produto de qualidade e resistente ao processo de higienização pelo menor custo conduziu a escolha pelo corte a laser do acrílico, como uma resposta à necessidade de aceleração do processo de produção, e que respondeu a um cálculo de tempo e custos. Havia alternativas a seguir: cortar outro tipo de plástico, ou produzir o EPI com suporte em acetato, como feito por outros grupos. Ao otimizar o desenho para o modelo composto por três peças, atingimos uma boa relação custo-benefício usando o acrílico, que tem o benefício de ser facilmente acessível no mercado local e higienizável pelas equipes. Esse processo de desenvolvimento de produto, produção e distribuição em meio a uma situação de restrição de movimento, desabastecimento de insumos e buscando atender uma necessidade emergencia,l demandou a organização de um sistema de logística usando ferramentas de compartilhamento online e alternativas de teletrabalho.

Nesse sentido, foi realizada uma pesquisa do serviço de corte a laser em empresas locais, e uma delas forneceu valores competitivos, entendendo a importância da ação de extensão. Isso fez com que fosse gerada uma demanda por serviço suficiente para que a empresa mantivesse, mesmo durante o momento de isolamento social e queda nas atividades comerciais, três empregos diretos, uma vez que a produção dos protetores faciais se tornou constante ao longo dos meses em que a iniciativa perdura.

Por fim, à medida que relatamos essa ação de extensão, o grupo continua motivado a fazer o melhor possível para ajudar na proteção das equipes de saúde do estado do Rio Grande do Norte, com a produção dos face shields, no atendimento aos pacientes infectados, beneficiando a sociedade como um todo para superar esse momento crítico. Enquanto houver recursos e insumos e por quanto tempo seja necessário, continuaremos a produzir.

\section{REFERÊNCIAS}

AGÊNCIA NACIONAL DE VIGILÂNCIA SANITÁRIA (ANVISA). Nota Técnica GVIMS/GGTES/ANVISA No O4/202O. Orientações para serviços de saúde: medidas de prevenção e controle que devem ser adotadas durante a assistência aos casos suspeitos ou confirmados de infecção pelo novo coronavírus (SARS-CoV-2). Brasília/DF, 2020.

ASSOCIAÇÃO MÉDICA BRASILEIRA (AMB). Falta de EPI preocupa OMS. Disponível em: https://amb.org.br/noticias/falta-de-epi-e-teste-para-coronavirus-tambem-preocupam-a-oms/. Acesso em: or de Abril de 2020.

CHU et al. Physical distancing, face masks, and eye protection to prevent person-to-person transmission of SARS-CoV-2 and COVID-I9: a systematic review and meta-analysis. The Lancet. Volume 295, issue I0242, p. 1973-1987, 27 de Junho de 2020.

FERGUSON et al. Report 9: Impact of non-pharmaceutical interventions (NPIs) to reduce COVID-I9 mortality and healtheare demand. 2020. Disponível em: https://www.imperial.ac.uk/media/ imperial-college/medicine/sph/ide/gida-fellowships/Imperial-College-COVI- 
Di9-NPI-modelling-I6-o3-202O.pdf. Acesso em: o5 de Maio de 2020.

FIOCRUZ. Covid-r9: a saúde dos que estão na linha de frente. Notícias. I3 de abril de 202O. Disponível em: https://portal.fiocruz.br/noticia/covid-r9-saude-dos-que-estao-na-linha-de-frente. Acesso em: 20 de Abril de 2020.

HOSPITALSanta Catarina recebe doação de máscaras para bebês. In: Agora RN. Publicado em 24/O4/202O às I4:34. Disponível em: https://agorarn.com.br/cidades/hospital-santa-catarina-recebe-doacao-de-mascaras-para-bebes/. Acesso em: O5 de Maio de 2020.

LABORATÓRIO DE INOVAÇÃO TECNOLÓGICA EM SAÚDE - UFRN. Mapas. Disponível em: https://covid.lais.ufrn.br/\#0-rn. Acesso em: o8 de maio de 2020.

NOME, Carlos; QUEIROZ, Natália. Acetate face shield for laser cutting. Disponível em: https://www.thingiverse.com/thing:4256259. Acesso em o8 de abril de $2 \mathrm{O} 2 \mathrm{O}$.

ORGANIZAÇÃO DAS NAÇÕES UNIDAS (ONU). OMS pede mais equipamentos e suprimentos médicos para enfrentar coronavírus. Disponível em: https:// nacoe Acesso em: O5 de Maio de 202O.sunidas.org/oms-pede-mais-equipamentos-e-suprimentos-medicos-para-enfre Acesso em: o5 de Maio de 2020.ntar-coronavirus/.Acesso em: oI de Abril de 2020.

ORGANIZAÇÃO PANAMERICANA DE SAÚDE (OPAS). Folha informativa - COVID-I9 (doença causada pelo novo coronavírus). Disponível em: https://www. paho.org/bra/index.php?option=com_content\&view=article\&id=6Ior:covidı\&\&Itemid=875. Acesso em: 23 de julho de 2020 .

PERENCEVICH, Eli N ; DIEKEMA, Daniel J ; EDMOND, Michael B. Moving Personal Protective Equipment Into the Community: Face Shields and Containment of COVID-I9. JAMA : the journal of the American Medical Association, Chicago, Vol.323(22). pp.2252-2253. o9 Junho de 2020.

PUPO, Regiane; GABRIELA, Celani. Implementando a fabricação digital e a prototipagem rápida em cursos de arquitetura: dificuldades e realidades. XIV Convencion científica de ingeniería y arquitectura. Anais... Congrasso SiGraDi. Havana, 2008.

RAYNA, Thierry; STRIUKOVA, Ludmila. From rapid prototyping to home fabrication: How $3^{D}$ printing is changing business model innovation. Technological Forecasting \& Social Change, Amsterdam, IO2. p. 2I4-224. 2016.

RIO GRANDE DO NORTE. Decreto no 29.54I, de 20 de março de 2020 . Define medidas restritivas temporárias adicionais para o enfrentamento da Emergência de Saúde Pública de Importância Internacional decorrente do novo coronavírus (COVID-19). Natal/RN, 2020.

SECRETARIA DA SAÚDE PÚBLICA (SESAP). Sesap divulga novos números da Covid-I9 nesta terça-feira (3I). Disponível em: http://saude.rn.gov.br/Conteudo. asp?TRAN $=\mathrm{ITEM} \& \mathrm{TARG}=228248 \& \mathrm{ACT}=\& \mathrm{PAGE}=\& \mathrm{PARM}=\& \mathrm{LBL}=\mathrm{NOT} \%-$ CDCIA . Acesso em: or de Abril de $202 \mathrm{O}$. 